\title{
Una metáfora para investigar en la cárcel
}

\section{Entre las múltiples significaciones del trabajo de campo que no podemos controlar}

\section{Gretel Schneider}

Facultad de Ciencias de la Educación (FCEdu), Universidad Nacional de Entre Ríos (iD) http://orcid.org/o0oo-0003-3522-2079

Correo electrónico: gretel.schneider@uner.edu.ar
Recibido:

29 de julio de 2020

Aceptado:

9 de febrero de 2021

doi: $10.34096 /$ runa.v42i2.8373

\section{Resumen}

La Unidad Penal N 1 de varones “Juan José O’Connor" de Paraná (Entre RíosArgentina), donde funciona la Escuela Primaria N 27 "Vicente Fidel López" era un territorio familiar para mí, desde hacía 10 años. Desde fines de 2005, soy parte de un grupo de universitarios extensionistas que iniciamos con los detenidos, diversos espacios educativos y culturales, desde la perspectiva de la comunicación comunitaria. Inicié la observación participante en la escuela en el año 2015, y esto me obligó a tomar decisiones acerca de cómo registrar y de buscar una metáfora para presentarnos en el campo en el cual yo ya estaba emparentada, ya que investigar está asociado a indagación policial o a la búsqueda de indicios que realizan las fiscalías en las denuncias penales. Sin embargo, esa metáfora no estuvo lo suficientemente bien elegida, ya que se generaron una serie de controversias entre los estudiantes, al principio y durante los primeros meses de mi estadía allí. Esto me permitió dimensionar lo que significa para quienes están privados de libertad compartir fragmentos de lo que piensan y sienten con alguien que no pertenece del todo a ese espacio, y la importancia de saber qué hacer con aquello que me cuentan. Asimismo, abordaremos la cuestión de moverse como pez en el agua en un territorio tan familiar como extraño, lo que nos permite reflexionar acerca de las posibilidades y límites de la "antropología en casa".

\section{Palabras clave}

Etnografía; Cárcel; Reflexividad; Trabajo de campo; Conflictos de sentido 


\section{A metaphor for investigating in prison. Among the many meanings of fieldwork that we cannot control}

\begin{abstract}
Key words

Ethnography; Prison; Reflexivity; Field work; Conflicts of meaning

The “Juan José O'Connor" Penal Unit No. 1 for boys in Paraná (Entre RíosArgentina), where Primary School No. 27 "Vicente Fidel López" operates, has been a familiar territory for me, for 10 years. Since the end of 2005, I have been part of a group of university extensionists that started with the detainees, various educational and cultural spaces, from the perspective of community communication. I started participant observation at the school in 2015 and this forced me to make decisions about how to register and to find a metaphor to present ourselves in the field in which I was already related, since investigating is associated with police investigation or the search for evidence that prosecutors carry out in criminal complaints. However, that metaphor was not well chosen enough as a series of controversies were generated among the students, at the beginning and during the first months of my stay there. This allowed me to gauge what it means for those deprived of liberty to share fragments of what they think and feel with someone who does not belong entirely to that space, and the importance of knowing what to do with what they tell me. We will also address the issue of moving like a fish in water in a territory as familiar as it is strange, allowing us to reflect on the possibilities and limits of "anthropology at home".
\end{abstract}

\section{Uma metáfora para investigar na prisão. Entre os muitos sig- nificados do trabalho de campo que não podemos controlar}

\section{Resumo}

Palavras-chave

Etnografia; Prisão; Reflexividade; Trabalho de campo; Conflitos de significado
A Unidade Penal "Juan José O'Connor" no 1 para meninos no Paraná (Entre Ríos - Argentina), onde a Escola Primária no 27 “Vicente Fidel López" opera, é um território familiar para mim há 10 anos. Desde o final de 2005, faço parte de um grupo de extensionistas universitários que começou com os detidos, vários espaços educacionais e culturais, na perspectiva da comunicação comunitária. Comecei a observação participante na escola em 2015 e isso me forçou a tomar decisões sobre como me matricular e a encontrar uma metáfora para nos apresentar no campo em que eu já estava relacionado, uma vez que investigar está associado à investigação policial ou à polícia. procurar evidências que os promotores realizem em queixas criminais. No entanto, essa metáfora não foi escolhida suficientemente bem, pois uma série de controvérsias foi gerada entre os estudantes, no início e durante os primeiros meses da minha estadia lá. Isso me permitiu avaliar o que significa para aqueles privados de liberdade compartilhar fragmentos do que pensam e sentem com alguém que não pertence inteiramente a esse espaço, e a importância de saber o que fazer com o que eles me dizem. Também abordaremos a questão de se mover como um peixe na água em um território tão familiar quanto estranho, permitindo refletir sobre as possibilidades e limites da "antropologia em casa". 


\section{De la extrañeza a ser del palo}

Luego de atravesar el puesto uno, el de acceso a la Unidad Penal $N^{\circ} 1$ de Paraná "Juan José O'Connor" (Entre Ríos, Argentina), suelo escuchar saludos y que gritan mi nombre desde la cancha de fútbol. Agitan sus manos al verme algunos muchachos, cuyos rostros no distingo demasiado a la distancia. Mientras avanzo en el camino de ingreso, desde los pabellones me preguntan cómo estoy, qué tal ando. Es habitual y me ocurre cada vez que atravieso el chapón, el portón de entrada a la unidad penitenciaria más grande de la provincia. "Acá todos te conocen", me dijo Juan, el maestro, cuando necesitó ayuda para llegar de un lugar a otro adentro del penal. Es que el taller de comunicación "La hora libre" y mi participación en la escuela me habían dado cierta popularidad entre los detenidos.

"La hora libre" es un espacio que desarrollamos junto con docentes y estudiantes de la Universidad Nacional de Entre Ríos a través de un proyecto de Extensión Universitaria del Área de Comunicación Comunitaria de la Facultad de Ciencias de la Educación. Con un dispositivo pedagógico que se transformó en un taller de comunicación comunitaria en un ámbito de encierro, iniciamos este camino a fines del año 2005, cuando yo estaba finalizando la carrera de Comunicación Social.

Mis primeros arribos al penal fueron a ciclos culturales que organizaba la Municipalidad de Paraná y a las funciones de un grupo de teatro que se había conformado en ese momento. En esas instancias es que tuve la experiencia inicial de entrar a una cárcel: me impresionaron las reglas para ingresar, las paredes pintadas a la cal, los alambres de púa, los guardias con las llaves de los muchos candados de las leoneras y las miradas tristes que ensombrecían las ocasionales risas.

El taller, así como otras actividades impulsadas por la institución universitaria, partió de una demanda específica, del deseo de un grupo de hombres detenidos de tener un lugar para la expresión y la creatividad.

El camino desde la extrañeza a la familiaridad en la cárcel fue largo y complejo. No puedo decir que jamás sentí miedo de la cárcel, porque no fue así. Una noche, antes de ir a uno de los primeros encuentros, en el noticiero local informaron sobre una pelea en un pabellón, con heridos graves de armas blancas -las tumberas-; fui al otro día realmente preocupada y me sorprendió que allí todos actuaran como si nada hubiese ocurrido y que de eso no se hablara. Lo pensé mucho antes de plantearlo a los compañeros presos, pero necesitaba decirlo. Por eso es que conté sobre lo que había escuchado por televisión, sin hacer preguntas ni dar más información que la vinculada a mis sensaciones y sentimientos. Fueron ellos quienes hicieron referencia a nuestra seguridad:

“- A ustedes no les va a pasar nunca nada acá en el taller, ustedes son como la visita ${ }^{1}$ y lo que ven en la tele son cosas que pasan todos los días en los pabellones, cosas de adentro." (De los registros del equipo extensionista).

En mis registros de ese momento escribí: "luego de que Jorge nos dijo esto mientras el resto asentía, me volvió el alma al cuerpo". Para comprender mejor esta situación, podemos decir que la criminalidad y el delito en ese momento se consideraban entre las principales inquietudes de la población en Argentina (Kessler y Merklen, 2013) y no estábamos fuera de eso.
1. La visita es la llegada de sus familiares y amigos. En general, se considera como el bien más sagrado que tiene un preso. 
Uno de los objetivos del proyecto de comunicación comunitaria en esa primera etapa era conformar un grupo, el de los palabreros, y se fue cumpliendo a medida que nos fuimos conociendo. $Y$, a pesar de nuestras buenas intenciones, ellos desconfiaban: un grupo de estudiantes y docentes de la facultad, que llegan al penal, algo están buscando, “¿ustedes nos vienen a estudiar?", preguntaban. Costó desterrar la usanza de los practicantes de psicología que llegaban a hacer entrevistas para no volver, y por ello recibíamos preguntas inquisitorias que con el tiempo se terminaron. De a poco, nos fuimos sintiendo como la visita, como parte de la familia, y esto implicaba que fuéramos oreja para angustias y frustraciones -como cuando la libertad venía con demoras- y para historias de vidas complejas, temas que surgían espontáneamente en el taller de comunicación. Ser palabrera también implicó conocer cuestiones de la cárcel por dentro que no aparecen a simple vista, que tienen que ver con el código carcelario, que integra un lenguaje, una moral, jerarquías, costumbres, una estética, etc.

En el encuentro final de 2006, dijo uno de los compañeros, Guillermo: "Aprendimos mucho de ustedes y ustedes de nosotros... ¡no puedo creer todo lo que ha aprendido Gretel!" (De los registros del equipo extensionista).

También con el tiempo encontramos la manera de tratar con los agentes penitenciarios, a distinguir sus jerarquías y a saber con quién valía la pena hablar y con quién no. Esto significó atravesar algunas situaciones de abuso de poder, requisas y cuestionamientos por parte del servicio. Estas prácticas aprendimos a considerarlas como aquello que ya viene con el uniforme; muchos celadores están acostumbrados a trabar todo lo que sea para el disfrute, la recreación o el crecimiento personal de los detenidos porque lo consideran una amenaza constante a la seguridad (Schneider, 2018).

La construcción de la confianza, asimismo, hizo que con varios muchachos nos volviéramos a encontrar en la calle, compartir asados y cumpleaños, una vez recobrada la libertad o las salidas transitorias.

La hora libre continuó, fue cobrando diversas formas. Desde hace casi 15 años, las producciones artísticas y comunicacionales son canales o excusas que facilitan procesos de producción colectiva y, con ello, de diálogo. La Radio Abierta Chamuyo FM es la posibilidad que tenemos, una vez al año, de abrir los micrófonos para toda la población penal y algunos visitantes y compartir algo de aquello que todos tenemos para decir. Esta fiesta, además, es muy conocida porque llegan grupos y músicos a tocar en vivo y suele tener repercusión en los medios de prensa local.

La vinculación sostenida con los palabreros es lo que me llevó a interesarme en la escuela. Una institución que todos los días funciona dentro de otra, gracias a otra y a pesar de otra, el Servicio Penitenciario. La Escuela Primaria $\mathrm{N}^{\circ} 27$ "Vicente F. López" acontece en un edificio que comparte con la Escuela Secundaria № 29 "Dr. Esteban Laureano Maradona". Tiene cuatro aulas y una oficina conocida como "la dirección". Allí se encuentra la directora con los profesores, también es el lugar donde se concentran las actividades administrativas, la biblioteca, y se usa como espacio áulico, ya que algunos estudiantes suelen recibir clases y apoyo escolar.

Etnografiar la escuela de cárcel es el desafío que emprendí estos últimos años y para el trabajo de campo que realicé en los años 2015 y 2016; me valió la 
experiencia y el reconocimiento del antecedente de participar de la Radio Chamuyo, pero en un nuevo rol, el de investigadora (Guber, 2011).

\section{Una metáfora para investigar en la cárcel}

La vinculación sostenida con los palabreros es lo que me llevó a interesarme en la posibilidad de etnografiar la escuela. Mi expectativa para investigar allí y lo que me impulsó a darle el marco de compromiso al postularme a una beca CONICET fue, justamente, la idea de manual de saberme contar con el rapport necesario. Consideré que era el elemento que le permite al investigador etnográfico evitar que los sujetos estén demasiado afectados por su presencia de manera que ella modifique las conductas y prácticas habituales de manera sustancial. "El investigador debe caer bien, ser confiable, simpático e incluso cálido. Todo esto será posible si el investigador es respetuoso y honesto en su expresión e impresión con el interlocutor" (Galindo Cáceres, 1997, p. 211).

Como dijimos, solo se trataba de aparecer en un nuevo rol, el de investigadora. Y además de cargar una libreta, llegué allí con una experiencia de muchos años, la cual merecía respeto tanto desde los estudiantes como desde los docentes. Como hemos aprendido, el respeto aparece como un valor básico y a la vez supremo en el penal y en la escuela; en el sentido que aquí nos referimos, es una devolución al mérito, como un gesto de gratitud a cierto tiempo de llegar a allí. A su vez, mi relación con el grupo de docentes de la primaria -y sobre todo, con la directora- comenzó luego de conocernos en los cruces en el Puesto 1 -el de ingreso y egreso al predio de la cárcel-. A su vez, con la escuela comenzamos a compartir algunas actividades como maratones de lectura y ciclos culturales como cine, música y teatro.

Yo era, de alguna manera, del palo. Por esto es que no sentí resistencias al comenzar a formar parte de los espacios cotidianos como aulas y pasillo de la escuela. Claro que mi inserción fue progresiva; unos meses antes de ir dos o tres veces semanales, comencé yendo cada quince días y con algunas excusas -como invitar al inicio del taller de comunicación, entrevistarme con la directora o gestionar la autorización en el Consejo General de Educación para poder hacer mi trabajo allí-. Todos en la escuela se mostraron muy abiertos y receptivos a mi presencia, desde el inicio.

A comienzos de 2016, con la aparición de un grupo de estudiantes de una carrera docente en calidad de practicantes, me di cuenta de algunos escollos que no debí atravesar por haber estado ya emparentada con la institución.

\footnotetext{
-Un alumno se me acercó a que le corrija un trabajo y me dijo despacito: ¿cuándo se va a ir toda esta gente del aula? ¡Y eso que eran unas pocas chicas jóvenes y lindas! -contó la maestra Loli una tarde antes de que llegasen los estudiantes a clases. (Del cuaderno de campo).
}

Mi ingreso al campo fue privilegiado. Incluso esos primeros días que llegué como investigadora, no necesité presentarme a mí misma, sino que en la escuela había estudiantes que, al conocerme del taller de radio, tradujeron mi llegada, si bien confusa: ¿cómo podía ser que una "maestra" de un taller viniese a la escuela y no lo hiciera como maestra?

Si bien el taller de comunicación "La hora libre" se constituyó como un espacio de horizontalidad, donde todos somos palabreros, en varias situaciones en 
las que me encontré con los muchachos luego de recuperar su libertad o bien ante su visita estando aún detenidos, me han presentado a su familia como una maestra del taller de radio.

Cierto es que el primer día que salí de mi casa para ir la escuela a observar, no fui con ansiedad ni nervios. Este estado comenzó cuando había traspasado el ingreso y estaba a metros de la puerta de la institución escolar. Necesitaba decir a qué comenzaría a ir y hablar de investigación sería desacertado, controversial, como un repelente para mis informantes. Antes de ese instante no lo había pensado porque estaba yendo al lugar de siempre con casi las mismas personas de siempre.

"Investigación" allí se asocia directamente a lo policial, a la investigación criminal para detectar un hecho en flagrancia -mientras está siendo cometido- o para esclarecer un delito -y esto es para buscar culpables y hacer acusaciones-; a los indicios y pruebas que buscan los fiscales para dar méritos a una causa en lo penal. Justamente, por haber sido foco de investigaciones es que la mayoría estaba allí, detenido, y todo lo que implica "haber sido investigado".

Expresar mis intenciones constituía un dilema que atraviesan habitualmente los etnógrafos (Bourgois; 2010; Guber, 2011; Sirimarco, 2012; Renoldi, 2014; Fassin, 2016, entre otros) al apostar por la forma de conocimiento que propone el enfoque que elegimos.

Uno de los primeros días en la escuela, cuando ya me sentía preparada para ir a participar de las actividades del aula -ya que previo a ello había establecido los acuerdos sobre mi estancia allí con la directora y desde el Consejo General de Educación habían extendido una resolución con los términos de mi participación-, iba a acompañar la clase de tercero B, ya que le había dado mi palabra, la semana anterior, a David, estudiante y participante de "La hora libre". Aquello había ocurrido un jueves, cuando salimos a recorrer las aulas con Florencia para contar acerca de mi presencia vinculada a mi investigación. Si bien la mayoría me conocía del taller de comunicación y la "Radio Chamuyo", algunos no.

En ese momento, mis palabras de presentación tuvieron que ver con mi trabajo desde hace muchos años, la tesis de licenciatura que ya había hecho y mi necesidad de conocer acerca de las cosas que pasan en una escuela de cárcel, un lugar que ofrece cosas distintas a las que pasan en los pabellones y en otros espacios del régimen. En ese momento, y ante algunas miradas que indicaban desconfianza, me vi en la necesidad de hacer una aclaración: no soy psicóloga, no soy detective, no soy periodista (ya que llegando a la escuela, cuando en mi cabeza ensayaba un speech, me imaginé que algunos podían interpretar que una de esas podría ser mi condición, sobre todo porque mi formación se vinculaba a esto último). Además, las expresiones confusas las noté aún sin acercarme ni un poco a la palabra "investigación". Vaya a saber las representaciones que esta tipificación podía generar en personas procesadas y condenadas judicialmente... ninguna abonaría a la circunstancia de estar-yo-parada-ahí.

Y luego de nombrarme por lo que no soy, lógicamente me inquietó (probablemente en un dilema conmigo misma) saber qué soy. En este caso sabía claramente lo que no era, ipero no podía aún definir lo que era! ¿Soy antropóloga? ¿Soy etnógrafa? ¿Soy comunicadora social? Un intento de todas estas cosas, posiblemente. Pero allí era una maestra del taller de comunicación que aparecía en la escuela sin intenciones de enseñar. Sino que vengo a aprender, es lo que le 
dije a cada uno de los muchachos que se acercaban con curiosidad, e indagaban acerca de lo que yo les iba "a enseñar".

"-Vengo a aprender para escribir un libro sobre ir a la escuela estando preso."

Trece palabras. Estas trece palabras fueron las que me hundieron.

\section{Escribir un libro fue mala idea}

Como venimos diciendo, mi objetivo era llegar al penal en calidad de investigadora después de haber ido como docente.

En aquel momento, yo pensaba que los muchachos pensarían que alguien que conocemos no nos puede traicionar. Pero no pensé que ellos se preguntarían: ¿acaso no era suficiente con lo que ya venía haciendo con nosotros (que es un "para nosotros")?, que es como decir: ¿tantas ganas de venir al penal va a tener esta piba?

Por aquellas primeras tardes de trabajo de campo, en la escuela se realizó una actividad de integración relacionada con la lectura de libros. En el salón común de la primaria y la secundaria se habían juntado muchos bancos que conformaban una especie de mesa gigante en la que se expusieron la mayoría de los libros con los que contaba la escuela; aún no habían llegado los estudiantes. La directora y las maestras me pidieron si podía contar los libros para saber qué cantidad se había dispuesto para la actividad y poder advertir luego en relación con los préstamos, porque uno de los objetivos era acercar a los estudiantes a los textos impresos para que les fueran prestados y los llevaran para leer en sus pabellones.

Mientras estaba yo sola en el salón contando los libros y las maestras estaban recibiendo en las aulas a los estudiantes para luego llegar todos al espacio común, pasaban por el pasillo los alumnos de secundaria y miraban con curiosidad los cambios en el espacio, que hubiese tantos libros y a mí en esa situación. Uno de ellos se acercó, su nombre era Hernán (revelé su identidad luego, ya que comenzó a participar del taller de comunicación) y me dijo:

“-Señora, usted que está acá con los libros, yo necesito que me consiga un libro, si me puede hacer el favor. Se llama "Los hijos del narco", y es de Daniel Enz.

- ¿Te interesa leerlo? -le pregunté con total ingenuidad.

- No, pasa que yo estoy en ese libro. O sea, el libro no habla de mí, eh. No es que yo soy hijo de un narco, sino que me dijeron que se cuenta algo que pasó y donde yo estuve. Y yo quiero saber si se cuenta tal como fue. ¿Usted me haría ese favor de conseguirme el libro? Yo se lo pagaría, ¿eh?.” (Del Cuaderno de campo).

Daniel Enz es un periodista de Paraná, quizás el más reconocido a nivel nacional, dueño de un periódico quincenal llamado Análisis, que se basa en el tratamiento de las noticias políticas provinciales y de lo que derivó un sitio de noticias, Análisis digital. A su vez, Enz escribe libros a partir de investigaciones periodísticas en las cuales denuncia tramas delictivas vinculadas a los personajes del escenario empresarial y político.

La pregunta de este joven me llamó la atención, pero no relacioné en ese momento su interés por aquel libro con mi intención de escribir un libro sobre la escuela. 
Sin embargo, la publicación de Los hijos del narco estaba generando un revuelo entre los detenidos de la unidad penal y muchos estaban viendo las formas de conseguirlo para ver qué decía y de quiénes: el tema estaba en los medios locales porque el libro estaba a punto de presentarse. Lo que en ese momento circulaba como rumor era que aparecían en el libro, como personajes, varios de los detenidos cuyas causas penales enfrentaban a unos con otros, muchos de los cuales se cruzaban en los pasillos de la escuela.

Desconociendo esto y sin haber advertido la señal que me había dado Hernán, el estudiante de la secundaria, yo había decidido hablar de escribir un libro porque, según mi perspectiva, los libros son lindos, se pueden ver, tocar, y porque un libro nunca le hace mal a nadie. Sin embargo, una serie de situaciones fueron indicándome que decir que iba a escribir un libro había sido una mala idea. A su vez, no tuve en cuenta que alguna vez un cronista de policiales me dijo que muchas veces los periodistas que realizan investigaciones en profundidad para luego ser publicadas, negocian con los informantes claves -que suelen ser los acusados- para que la publicación del resultado final salga a la calle antes del juicio, justamente por la incidencia en la opinión pública y, por tanto, en la de los jueces que deben generar una sentencia en la causa.

En 2015, el grupo de estudiantes del tercero A me había sido definido por un maestro como el aula donde todos son narcos, una nochecita en la que caminábamos de regreso a nuestras casas, después de clases. Pues en esa aula es donde comenzó el revuelo sobre mi libro; la directora me dijo unos pocos días después que mencioné que estaba allí para escribir uno:

- Hablan de tu libro. Dicen que les preocupa que las cosas que vos escribas puedan llegar a comprometer sus causas, sus situaciones penales. Bueno, yo les dije que no era así, que jamás harías eso, que hace mucho que venís al penal a dar el taller de comunicación y que a vos no te interesaban sus causas. Que venís a la escuela para saber de la escuela. (Del Cuaderno de campo).

Utilizaron a las maestras, a la directora para saber más, para pedir explicaciones de mi presencia y para desentramar qué hacía yo allí, y no fue porque no me tenían confianza, sino porque ¿no estaba acaso asaltando la confianza construida? Y no se trataba de secretos que no podían ser revelados, sino de miedo o desconocimiento en cuanto a lo que podían llegar a decir y al salir de ahí sea mal traducido o malinterpretado. ¿Podría ser yo una informante (Renoldi, 2014, p. 123)?

Ese mismo día, ya cuando los estudiantes se habían retirado del edificio escolar con el coordinador; me encontré en la puerta con Facundo (quien había participado alguna vez del taller de comunicación y quien iba la secundaria) y Adrián (de segundo nivel de la primaria). Me dijo Facundo:

- Señora ¿cuál es su título? Licenciada en Comunicación Social, le respondí.

- Sí, si ella le hacía los discursos a los políticos -afirmó Adrián, como en una intención de otorgarme importancia.

-¿Qué? No, yo nunca me dediqué a eso - respondí asombrada por la representación construida.

- ¿Ah, no? Bueno, eso me dijeron -respondió Claudio. (Del Cuaderno de campo)

Varios elementos abonaban a la confusión general. ¿Quién me mandaba? ¿Los de arriba? Esas circunstancias me permitieron explicar lo que días atrás me advirtió un estudiante: 
“- Si por ahí vas a soplar bolsa arriba -en relación con ir contar lo que pasaba en la escuela a las oficinas de Tratamiento Penal, donde se establecen las progresiones del cumplimiento de las penas-, deciles que me está yendo bien en la escuela." (Del Cuaderno de campo)

Sin dudas, podía ser yo quien llevara información de primera mano que a otras personas nuevas o desconocidas les negarían, por esa cercanía que yo portaba. ¿Acaso estaban buscando negociar los límites de mi investigación (Sirimarco, 2012); desconfiando?

Esta pregunta me obligó a distinguir y a no perder de vista que aquello que estamos investigando no es sino esa posición que jugamos en el campo, lo que construye un conocimiento sobre los otros en relación conmigo misma y, sobre todo, un conocimiento de mí misma.

¿Podría realmente llegar a ser del palo siendo mujer, clase media, escolarizada en los tiempos y formas que el sistema educativo impone y sin tener en mi historia conflicto alguno con la ley penal? Esa sensación de familiaridad ¿me impedía percibir/ percibirme? ¿No estaba acaso mimetizada pero sin engañar más que a mí misma?

Los años de experiencia, ese saber sobre la cárcel y sobre esa cárcel, que me permiten moverme como pez en el agua en el territorio, en cuanto al extrañamiento necesario para etnografiar, no es más que un camuflaje. Un intento de asemejarme a los otros, sujetos a los que fui a conocer con fines posados en la investigación, que también podría significar el desarrollo de un proyecto o una idea compartida, como es habitual en mi rol de extensionista.

Aquí, sin dudas, entra en juego la autoridad etnográfica (Strathern, 1987) porque la expectativa sobre lo que otros cuenten sobre ellos y cómo lo hagan no es lo mismo hacia alguien que es extraño, ajeno, a alguien como yo, que coqueteo con cierta familiaridad. Como aquellos roles de parentesco ficticio (Lins Ribeiro, 2011) que se construyen en el TC, puedo decir que no integraba el clan, ya que soy portadora de otros rasgos culturales, unos que difícilmente encastren allí. Sin embargo, la relación parte de una adopción construida de forma mutua, basada en un padrinazgo de muchachos privados de libertad, por quienes también fui bautizada, ${ }^{2}$ que implica cierto acceso a su mundo, a su vida cotidiana.

Razones estas que implicaron que mi producción final estuviera necesariamente ligada a los deseos e intereses de esos sujetos con los cuales compartí la práctica escolar, estudiantes y docentes.

-Ya que te gusta tanto venir acá a estudiar -me dijo en tono propositivo Coco en un recreo- ¿qué te parece si vos tomás mi lugar y yo el tuyo, por un día? Y ando en la calle, así como vos. Aunque -dudó volviendo a revisar sus palabras-no va a poder ser porque a vos te tienen que ingresar allá enfrente -culminó señalando en dirección de la unidad penal femenina, cuyo predio está en la vereda opuesta a la de varones-. (Del Cuaderno de campo)

Más allá de la evidencia de que el género nos hace diferentes..., en caso de ser factible ese juego: ¿accedería yo a ese canje de posiciones? ¿A ponerme en su lugar y estar un día presa, ya que tanto me gusta ir allí con ellos? Seguramente no, porque no tengo la certeza acerca de que se mantendrían esas reglas tal
2. Muchas veces y como un apodo, "Greta" era la manera que me llamaban en la escuela, si bien sabían que mi nombre de pila es "Gretel”, así como ellos encuentran nuevos modos de nombrarse por los compañeros del pabellón o los amigos del barrio. Los estudiantes de la escuela que iban al Taller de Comunicación me decían “Gretel” en el taller y a veces "Greta” en la escuela. De esta manera, percibí que esa modificación de mi nombre de pila no era por malentendido, sino porque renombrándome comenzaron a darme cierta pertenencia. 
y como yo las conozco, ni si sobreviviría a ello. Ahora bien, esa lejanía y la imposibilidad de ese canje también constituyen mi afinidad sobre lo carcelario.

\section{Las diferencias entre un libro y otro}

Mientras yo me hacía preguntas para la tesis, ellos se preguntaban por mi libro: ¿Qué va a decir, sino lo jugoso de las historias de vida de los presos, sus raids delictivos, sus roces con personalidades de la escena pública, las veces que estuvieron cerca de caer en cana y zafaron? ¿Qué iba a hacer yo con lo que veía y escuchaba en la escuela? ¿Iba a pedir nombres, fechas? ¿Cuánto los iba a hacer hablar? ¿Qué relato sobre ellos iba a construir sino uno que estuviera en sintonía con las formas en que los medios de comunicación cuentan y cristalizan (Molina, 2010) cierta imagen social del preso?

La sospecha no se trataba de aquella que pone el etnógrafo como quien analiza o escruta poniendo en foco a alguien a partir de un prejuicio, de una perspectiva determinada o desde una teoría científica (Sirimarco, 2012, p. 271). Sino que encarnaba yo un fantasma mucho más tangible y una amenaza de algo que estaba siendo real, porque un libro circulaba y tenía el poder de arruinarlos si incidía en sus juicios, en el cumplimiento de sus condenas (quizás como una fantasía, o no). Pero más allá de eso, eran legítimas sus dudas.

A su vez, no podían evadirme, porque no era yo una desconocida sino que era Gretel, la del taller de comunicación y, además, no estaba constantemente haciendo preguntas, sino que, simplemente, estaba. Estaba tres días a la semana, un rato sentada en las aulas y el resto del tiempo en el pasillo.

Esa afinidad que construí en muchos años con los detenidos de la Unidad Penal $\mathrm{N}^{\circ} 1$ hicieron que me ponga en vigilante sobre que no se malinterprete mi lugar de etnógrafa en la escuela, justamente por preservar la historia del taller de comunicación. Por eso es que a raíz de la cuestión de mi libro, cambié algunos detalles en mi actitud de observadora participante.

Comencé a llegar con una libreta que decidí no celar, para que no pensaran que los estaba investigando. Mis notas estuvieron siempre disponibles para que leyeran y habláramos de ello, me preguntaran -y también, me informaran-. Juani, quien solía manifestar cierta desconfianza a que yo estuviera en el aula escribiendo, una vez se puso a mirar mi cuaderno de campo y rastreó todas las veces que yo lo había mencionado. Luego, me dijo: "pensé que nadie más que yo se había dado cuenta que la gotera del techo me daba en la espalda. ${ }^{3 \prime \prime}$ (Del Cuaderno de campo) muy descuidado en su infraestructura, los días de lluvia el agua penetraba en el cielo raso, y aquel día, bajo la gotera estaba Juani. Yo me había ubicado detrás de él y observé cuando -sin decir nada-decidió ponerse la campera de lluvia dentro del aula porque se estaba mojando por las gotas que se desprendían del machimbre en mal estado. Y esto que vi, lo anoté en mi libreta con palabras sueltas.
Y a partir de esa situación de interacción, su actitud hacia mí fue diferente. Ya que los dos habíamos percibido la gotera sobre su espalda, decidió dejar de lado las sospechas o los cuestionamientos, que no me molestaban, sino que los consideraba parte del juego. Quizás porque yo fui quien en ese momento percibió lo mismo que él, o porque esa escena no pasó desapercibida ante mi mirada.

El libro de Daniel Enz, mientras tanto, estaba reviviendo internas de allí adentro, revelando distintas causas penales con nombres y apellidos y haciendo asociaciones que los presos comentaban que carecían de precisión y exactitud. Los estudiantes no se me acercaron a preguntarme directamente acerca 
del tema, si bien la cuestión se me fue acercando cada vez más y, a su vez, tomando otras formas.

Un día, en el horario de la siesta, yo iba caminando desde el centro de la ciudad hasta la Unidad Penal $\mathrm{N}^{\circ} 1$ a una función de teatro. De camino me encontré con Julio, un muchacho que estaba con salidas laborales ya muy cerca de cumplimentar su condena y que ya había salido de trabajar y estaba tomando una cerveza frente a un kiosco, de cuclillas en una esquina cerca del penal, con otro compañero que estaba apoyado en una bicicleta, en la sombra que les daba un mullido paraíso. Los saludé y me quedé con ellos, charlamos un ratito. Me contó que hacía unos pocos días que ya estaba habitando el pabellón de preegreso y que antes de eso:

- En el pabellón me comentaron que estás yendo a la escuela pero que no vas como maestra, que querés escribir un libro con las cosas que se hacen ahí, no con lo que pasa, sino con lo bueno -me dijo haciendo una comparación que entendí que tenía que ver con mis intenciones.

- Sí-les dije mirándolos a los dos fijamente de una forma de comprometerlos a ser portavoces de lo que se venía-, yo sé que en los pabellones se habla de eso y tengo miedo de que me malinterpreten creyendo que voy a botonear algunas cosas. Si bien una vez que me conocen me preguntan a qué voy, yo les explico y está todo bien. Julio cerró los ojos sonriendo, luego me miró de la misma manera en que yo lo había hecho y me ofreció cerveza de la que estaba tomando en un pequeño vasito descartable de café; cambió la pierna de sostén en su posición de cuclillas:

-A vos te tiene que importar lo que piensan de vos los que te conocen. Es así. Y de una, si te vienen con un berretín, vos le decís clarito: mirá, te lo voy a decir en tumbero porque yo no soy ninguna cheta, así como soy de rubia no me venden manzana podrida, no me va ni la careta ni soy verduga, ite va o no te va? (Del Cuaderno de campo)

¿Acaso debía aprenderme ese discurso? Cierto es que el encuentro con Julio me había dado pistas sobre la percepción de los sujetos en cuestión sobre mis intenciones de escribir un libro. Acaso ¿no es este poder de decir "cómo son las cosas realmente acá" con el respaldo que me otorga ser del palo lo que me permite ese coqueteo con la familiaridad? Considero, o mejor dicho, sospecho que todo lo que me alejó, en algunos momentos, me acercó. Cada uno de los aspectos que me distinguía de ellos -los estudiantes de una escuela primaria que funciona en un penal- es el colchón de un depósito de confianza; y que si ello no fuera así (yo ante ellos) me convertiría en real. Dejaría ese lugar ficticio de bisagra, de poder jugar desde adentro y desde afuera, pero con sus códigos, esos que requieren aplicar la tumba, si me vienen con la tumba.

Al parecer, mis objetivos comenzaban a diferenciarse del libro de Enz.

Unos días después, en el tercero A, estaba sentada junto con el grupo como habitualmente y la maestra Laura, antes de empezar su clase, dijo:

- Está Gretel con nosotros. Estaría bueno que charlemos con ella, esto de que algunos habían comentado que tenían miedo que en su libro se digan cosas que los comprometa en sus causas, como ocurre con el libro de Daniel Enz, "Los hijos del narco" -su planteo fue directo y algunos estudiantes me miraron y otros bajaron la cabeza.(Del Cuaderno de campo)

Sin haberlo planificado con la maestra, ella me dio el pie para que yo pudiera hacer una comparación entre la investigación periodística y la que hacemos 
en la universidad, cuestiones que reconozco claramente distintas por oficio y formación. A lo que agregué:

-En mi caso, estudio sobre la educación y lo que me interesa saber es cómo es la escuela de cárcel. No me importan sus causas, sino me interesan ustedes como estudiantes, como integrantes de esta comunidad educativa, como alumnos de tercero. Me parece interesante hablar de esta escuela porque, si no venís al penal, no la ves, nadie la ve. ¿Cuántas son las personas de afuera que saben que los presos estudian en una escuela? (Del Cuaderno de campo)

Los estudiantes me miraron y asintieron. Sobre la cuestión de mi libro, quise dejar en claro las implicancias en relación con que mi producción final se vincularía estrechamente a los deseos e intereses de esos sujetos con los cuales compartí la práctica escolar, estudiantes y docentes.

Esas primeras semanas seguí yendo pero evité mencionar lo del libro. Una tarde, en clases, en que yo estaba sentada al final del aula de segundo año, en un banco junto a un estudiante, entró Adrián, un compañero del taller de comunicación que siempre circulaba con libros que conseguía en la biblioteca del penal; en ese momento estaba cargando uno sobre la vida de JFK. Me saludó y me preguntó, en voz baja pero lo suficientemente alto como para que los más cercanos escuchen:

“- ¿Cómo se va a llamar tu libro?

- El título se pone al final, pero te aviso que escucho sugerencias -le respondí."

El tema volvió a surgir en vísperas de las elecciones presidenciales de 2015, porque en los medios de comunicación se había instalado la cuestión de las condiciones de vida en las cárceles, a partir del argumento de la mano dura; los sentidos que se reproducían tenían que ver con que los presos vivían demasiado bien. Alberto, de tercero A, reproduciendo el discurso de campaña de Sergio Massa dijo:

-En Buenos Aires, los presos cobran 6 mil pesos por mes y acá nos pagan unas monedas, estamos remal. Yo me voy a ir a un penal de Buenos Aires.

- Es verdad, acá hay compañeros que cobran 80 pesos y laburan un montón. (Del Cuaderno de campo)

De repente, todos hablaban en simultáneo y el tema me llevó a intervenir y levantar la mano, para dar mi opinión.

-Esto que estamos charlando es lo que dicen en la tele, ¿no? Bueno, los medios de comunicación muchas veces cuentan las cosas que quieren contar a la manera en que desean hacerlo y esto hace que se genere odio en la gente, por ejemplo, con esta versión de los sueldos de los presos. Que, además, no es cierto. Ya que hay penales federales que venden mano de obra a empresas y son las empresas las que pagan esos salarios, que en todo caso es lo que corresponde por ley. Lo que se remunera es el trabajo, y ustedes ya saben que nunca el salario de un preso es como el de una persona que no está en situación de cárcel. Siempre se busca aprovechar la situación a favor de los sectores empresariales o el Estado - dije mientras todos me miraban y estaban en silencio.

En ese momento, Gabo me preguntó:

-Y cuando escribas tu libro, ¿vas a tirar para el lado de ellos o para el de nosotros? (Del Cuaderno de campo)

En esta pregunta el estudiante posicionó, de un lado, a un adversario casi invencible: el sentido común, los medios de comunicación; y del otro lado 
el nosotros, esos quienes estaban allí. Era mi oportunidad de contrastar las diferencias entre el libro que andaba dando vueltas y el que yo pretendía escribir y que sería para quién sabe cuándo, tal vez yo lo terminaría en un tiempo suficientemente largo como para que pudieran salir de la cárcel con sus condenas cumplidas.

-Voy a hablar de lo que pasa acá en la escuela, de lo que veo, pero obviamente a partir de lo que yo creo. Lo que pasa acá es algo que nadie viene a ver, ¿o no es así? Cuando se habla del libro de Daniel Enz, que es del libro que todos hablan porque habla de personas que conocemos, que están detenidas. Y yo les pregunto: ¿Ustedes lo conocen a Enz? ¿Lo han visto venir al penal? ¿Ha venido a charlar con ustedes o con las personas de las que habla en su libro? (Del Cuaderno de campo)

Mi perorata los dejó sin palabras. No respondieron nada y, de alguna manera, mi libro se transformó en algo que iba a reivindicar el lugar de ese nosotros, algo que estaba muy alejado de mis intenciones. A partir de eso, muchas veces los estudiantes de tercero B llegaron a la escuela y me dijeron algo así como: tenemos algo para contarte para el libro y luego que yo te lo digo así nomás, vos vas a saber cómo contarlo.

Lucas, una tarde en el pasillo, mientras compartíamos los cinco minutos de recreo, quiso relatarme una situación que había vivido en su pabellón. Me dijo:

-Yo a vos te lo cuento porque te tengo aprecio y porque vos estás haciendo un libro. Yo estoy acá adentro y soy el que ve toda la injusticia. Te lo estoy diciendo con el corazón. Quizás haciendo un libro, todos los problemas y todo lo que pasa acá, cambia.

- ¿Y a vos no te parece que contándome todo esto no estás botoneando? -le pregunté e inmediatamente se empezó a reír.

-No me parece, porque estas son cosas que me pasan a mí. No estoy diciendo quién es quién. Te cuento lo que me está pasando a mí. Yo soy preso y lo único que odio son los botones. (Del Cuaderno de campo)

En algunas oportunidades han apostado a mi libro como el cáliz de la justicia: "porque vas a decir las cosas que nos pasan a los presos y que nadie sabe, que nadie quiere ver, cómo son las cosas realmente acá". (Del Cuaderno de campo). Además de en cada ocasión tratar de moderar esas ilusiones, me solía inquietar lo que ellos imaginaban sobre lo que yo relevaba y a lo que le prestaba atención. Otro muchacho, José, un día que estaba en duda sobre si seguir yendo a la escuela o no porque se sentía muy sumergido en los problemas que acaecen en el pabellón y quería hablar de ello, me manifestó:

“-Porque vos además de escribir sobre lo que hacemos en la escuela y sobre nuestros sentimientos, también vas a decir cosas de la vida carcelaria que nadie dice." (Del Cuaderno de campo)

\section{Un guiño y algo que aprendí}

De alguna manera, los vestigios de desconfianza se diluyeron durante el proceso de compartir las clases y los espacios de la escuela. A los estudiantes de secundaria que transitaban el pasillo delante de las aulas de primaria hasta llegar a su escuela, si no me conocían, les llamaba la atención mi presencia.

Una tarde un muchacho les dijo a los estudiantes de primaria con quienes estaba yo charlando, mientras me miró fijamente: 
- ¿Tienen profesora nueva?

-No - le respondí aprovechando la oportunidad para nombrarme ante los estudiantes de tercero $\mathrm{A}$, a quienes les hice un guiño, ya que les hablaba a ellos pero me miraba a mí-. No soy profesora, soy alumna. No vengo a enseñar, vengo a aprender.

- ¿Y a qué año? -Siguió insistiendo.

-A todos. (Del Cuaderno de campo)

Los alumnos de primaria que estaban junto a mí sonrieron como en complicidad. Sentí alivio por la forma en que prestaron un guiño y pensé que ya tendríamos más tiempo de hablar juntos sobre los alcances de "mi libro" y de evacuar las dudas sobre la exposición de sus historias y de lo que me contaban.

De la forma en que la experiencia me encontró, podría advertir que pueden ser muy dinámicas las condiciones de la familiaridad; el trabajo de campo me llevó a encontrarme en la diferencia y en las lecturas compartidas, que vuelven complejo mi punto de vista. Si bien es cierto que esto de la familiaridad me ha permitido acceder a integrar espacios y a compartir diversas situaciones del adentro, también me invitó a confundirme, a ver borrosos ciertos límites que me entorpecieron no sólo el comienzo del TC en la escuela sino el proceso de extrañamiento, al identificarme con ellos en su condición humana.

Uno de los problemas fue no haber tenido en cuenta que "el campo no es una instancia mansa a la espera de la observación del etnógrafo, sino el resultado de encuentros y confrontaciones" (Sirimarco, 2012, p. 289). Y, además, que cuando hacemos trabajo de campo, focalizamos en cómo y qué comunican esos sujetos de quienes vamos a aprender, y ya hemos visto que es tanto o más importante lo que comunicamos llegando a ciertos lugares en actitud difícil de codificar, y sumado a referencias previas que no encajan demasiado. Toda esta cuestión de mi libro me indicó que jamás hay que minimizar la explicitación del "a qué voy" en el TC, y que es una referencia muy importante cuando hay cierta familiaridad puesta en juego. Estaba con personas que conocía de antes, dominaba el universo vocabular y aun así fui sospechada de estar develando lo que no puede salir de allí.

Entonces, me atrevo a reconocer que no se puede relativizar la cuestión del "rapport" (Bartolomé, 2003) y a reconocer que aprendí que no podemos echarnos a descansar a sabiendas de que un vínculo ya ha sido construido, sino que la empatía o la aceptación son procesos inacabados, que continuamente están siendo.

La familiaridad puede ser una arma de doble filo o una capa de invisibilidad, que muchas veces necesitamos quitarnos. Permite no requerir tantos traductores, encontrar más fácilmente las fuentes y los informantes, y "más naturalmente" pueden esconderse las dudas o las desconfianzas que inevitablemente aparecen cuando llega alguien a hacer algo que no está muy claro y se pone a observar.

Algo que nos aporta, en este sentido, el campo de la comunicación social, es no perder de vista al lector; porque por más que conozcamos el campo y que sintamos la confianza de movernos como pez en el agua, hay sentidos que podemos no estar percibiendo nosotros pero sí son advertidos por nuestros "otros". 
Quizás, en este camino de varios años en los que vengo vinculada al territorio carcelario, fue mi principal desafío cambiar mi mirada de extensionista experimentada y ponerme los anteojos de investigadora con todo por conocer. Como un juego de aproximación y distanciamiento (Lins Ribeiro, 2011), necesario en todo trabajo etnográfico, traté de ir "poniendo entre paréntesis, suspendiendo el conocimiento contextual asumido normalmente como compartido (sobre la base de las experiencias precedentes de interacción)" (Wolf, 1988, p. 119), para reconocerme en otro lugar, el de forastera que busca los parámetros para poder moverse. Una búsqueda basada en mirar y escuchar, ya que "ambas se complementan y sirven para el investigador como dos muletas [...] que le permiten caminar, aunque sea torpemente, en el camino del conocimiento" (Cardoso de Oliveira, 1996, p. 16).

Ese libro que inventé porque me pareció acertado y del que hablé con los estudiantes en el pasillo y en las aulas y que fue comparado con un libro que parecía cercano pero estaba lejos me habló de eso a lo que fui a ese lugar.

Llegué para, a través de una etnografía, mostrar cómo es el acontecer de una escuela en un ámbito de privación de libertad, cómo son las relaciones que se establecen entre dos instituciones del Estado que conviven a pesar de funcionar desde distintas lógicas y normas; de qué manera aparece y qué lugar ocupa el derecho a la educación en este entramado y qué significa la escuela para los presos que participan de su vida cotidiana.

La reacción de los estudiantes a mi libro, considero -con el paso del tiempo y en las nuevas escrituras que un recorrido nos permite- que no fue una manera de proteger, de defender, y no a ellos mismos individualmente sino a la escuela y a lo que ahí pasaba, a lo que cada uno depositaba allí a diario estableciendo lazos, intercambiando saberes y mostrándose de una manera que no tenía nada que ver con sus prontuarios judiciales.

La sospecha en la que me encontré envuelta tenía que ver con esas formas de expresión que muestran a la cárcel de otra manera. Si bien al difundirse estas cuestiones quizás abonarían a resignificar ese lugar social que hace que sus condenas -las que parten de las estigmatizaciones- continúen aún en libertad y que, ante la amenaza de que lo que pasa ahí salga a la luz, de que lo definido por ellos como lo bueno trascienda, desconociendo los alcances, preferían celarlo y protegerlo, por ser algo de ellos y justamente por la posibilidad de ser mostrados de otra manera, de una manera en la que jamás fueron narrados.

Como hemos intentado contar, los sujetos con los que nos encontramos nos abren sentidos pero a su vez nos plantean un desafío tras otro, y es la capacidad ilimitada de lo inesperado que tiene el trabajo de campo y lo que hace que la etnografía sea una forma de conocer tan emocionante.

Años más tarde, me acordé de que no tuve en cuenta una metáfora mucho más fértil que me reveló un muchacho luego que le conté de mi libro: "yo pensé que venías a hacer una pasantía." (Del cuaderno de campo). 


\section{Financiamiento}

El trabajo fue realizado mediante una beca doctoral CONICET.

\section{Agradecimientos}

Gracias al apoyo, orientación y compañía de mi directora de tesis, Patricia Fasano y al INES UNER/CONICET.

\section{Biografía}

Gretel Schneider es comunicadora social y trabaja como docente, extensionista e investigadora de procesos de comunicación comunitaria y de comunicación/ educación en contextos de encierro. 


\section{Q Referencias bibliográficas}

" Bartolomé, M. (2003). En defensa de la etnografía. El papel contemporáneo de la investigación intercultural. Revista de Antropología Social, 12, pp. 199-222. Recuperado de http://www.redalyc.org/articulo.oa?id=83801210

"Bourgois, P. (2010). En busca de respeto. Buenos Aires: Siglo XXI.

»Cardoso De Oliveira, R. (1996). El trabajo del antropólogo: mirar, escuchar, escribir. Revista de Antropología, 39(1), 13-37.

"Fassin, D. (2016). La fuerza del orden. Buenos Aires: Siglo XXI.

» Galindo Cáceres, J. (1997) Sabor a Ti: Metodologia Cualitativa en Investigación Social. Xalapa: Ed. Universidad Veracruzana.

"Guber, R. (2011). La etnografía. Método, campo y reflexividad. Buenos Aires: Norma.

» Kessler, G. y Merklen, D. (2013). Una introducción cruzando el atlántico. En R. Castel, B. Kessler, D. Merklen y M. Numa. Individuación, precariedad, inseguridad ¿Desinstitucionalización del presente? Buenos Aires: Paidós. Pp. 9-23.

»Lins Riveiro, G. (2011). Descotidianizar. Extrañamiento y conciencia práctica, un ensayo sobre la perspectiva antropológica. En M. Boivin, A. Rosato y V. Arribas (comps.), Constructores de Otredad. Buenos Aires: Antropofagia

" Molina, L. (2010) Historias de la villa. La representación discursiva de los pobres y la pobreza urbana en los diarios. Revista Texturas, 9(9/10), 169-181.

» Renoldi, B. (2014). El secreto, el informante y la información: indagaciones reflexivas sobre la etnografía y la investigación policial. En R. Guber (Comp.), Prácticas etnográficas. Ejercicios de reflexividad de antropólogas de campo. Buenos Aires: IDES; Miño y Dávila. Pp. 88-113.

"Schneider, G. (2018). Cuando la escuela acontece en la cárcel. Revista Contexto de Educación, 24, 3-13. Recuperado de http://www2.hum.unrc.edu.ar/ojs/index.php/contextos/ article/view/727

"Sirimarco, M. (2012). El policía y el etnógrafo (sospechado): disputa de roles y competencias en un campo en colaboración. Etnográfica, 16(2). Pp. 269-290. Recuperado de http://journals.openedition.org/etnografica/150o

» Strathern, M. (1987) Los límites de la auto-antropología. En A. Jackson (Ed.), Anthropology at home (pp. 16-37). Londres y Nueva York: Tavistock Publications.

»Wolf, M. (1988). Sociologías de la vida cotidiana. Madrid: Cátedra. 
